\title{
A PRÁTICA FÍSICA E DESPORTIVA NO 1o CICLO DO ENSINO BÁSICO: Falando de Modelos Sustentáveis para a Educação E Saúde
}

\author{
Maria Isabel Condessa ${ }^{1}$
}

\begin{abstract}
RESUMO
O início da Educação Básica é um momento fulcral na educação para a atividade física (AF), e, embora desde cedo se preveja a oferta na escola de um conjunto de práticas físicas, lúdicas e desportivas relevantes para as necessidades das crianças e jovens, nem sempre essa intenção se concretiza nas escolas. Nesta comunicação pretendemos realçar a importância de uma educação/formação desenvolvida em dois modelos complementares: com a Educação Física, lecionada em horário curricular pelo professor especialista de Educação Física (EF) e, algumas vezes, pelo professor titular de turma; com um Programa de Desporto Escolar, em práticas que decorrem em atividades extracurriculares, propondo uma oferta em animação e iniciação à prática física e desportiva (AFD) em várias modalidades significantes para a criança e a cultura da região em que vive. Sugerimos, aqui, uma análise desta realidade em um modelo de práticas sustentáveis para as escolas do 1ำ ciclo que têm permanecido "em parte" do todo nacional, mesmo após as fortes mudanças da última década. Esta é uma oportunidade de refletir a partir destes modelos de prática de EF e AFD, que, de uma forma sustentada, se propõem a criar melhores condições de vida às crianças, assegurando-lhes uma equidade de oportunidades - criação de hábitos mais saudáveis e comportamentos mais ativos.
\end{abstract}

Palavras-chave: Educação e saúde. Prática física e desportiva. Escola. 1o ciclo do ensino básico.

THE PHYSICAL ATIVITY AND SPORTS IN THE 1ST CYCLE SCHOOL: SPEAKING OF SUSTAINABLE MODELS FOR EDUCATION AND HEALTH

\begin{abstract}
The beginning of education is a key moment for physical activity (AF), and although early in the school provision of a set of physical, playful and sport practices, all relevants to the needs of children and young people, it's not always materializes in the schools. In this communication we intend to highlight the importance of an education / training developed in two complementary models: 1 . with the Physical Education (PE), taught as curricular matter by the specialist teacher of PE and, sometimes, by the primary teacher; 2 . with a School Sport Program, in practices that take place in extra-curricular activities, proposing an offer in animation and initiation in physical ativity and sports (PAS) in several significant activities for the child and the culture of the region in which he lives. We suggest here an analysis of this reality, through a model with sustainable practices for 1st cycle schools, which have remained "in part" of the national whole, even after the strong changes of the last decade. This is an opportunity to reflect from these PE and PAS practice models, which in a sustained way aim to create better living conditions for children, ensuring them an equal opportunity - creating good heather and more active behaviors. Keywords: Education and health. Physical ativity and sports. School, $1^{\text {st }}$ cycle.
\end{abstract}

RECEBIDO EM: 28/11/2018

ACEITO EM: 5/1/2019

\footnotetext{
${ }^{1}$ Centro de Investigação em Estudos da Criança, Universidade do Minho, Portugal. Faculdade de Ciências Sociais e Humanas, Universidade dos Açores, Portugal.maria.id.condessa@uac.pt
} 
$\mathrm{Na}$ escola, o propósito pedagógico de enriquecer o repertório físico e motor, assim como as atitude e comportamentos das crianças e jovens, passa pela proposta de um conjunto de práticas físicas e motoras. Mesmo as atividades mais simples, com um carácter lúdico e sociorecreativo, têm um contributo positivo na infância, fase que se caracteriza por ser simultaneamente rica em oportunidades e em situações críticas. Estas práticas exercem influência nas crianças e jovens na sua capacidade de superação física e mental, na aceitação de comportamentos e valores sociais e na criação de hábitos de vida saudáveis, tudo aquisições essenciais ao seu "bem-estar".

A Convenção das Nações Unidas sobre os Direitos da Criança (20 de Novembro de 1989) e, mais atualmente, a própria Unicef (CONVENÇÃO..., 2004), colocaram como prioridade o direito da criança à educação. É por isso que quando falamos na prática física ou desportiva tratamos de um direito à educação, no sentido de permitir que se obtenha um dos seus principais objetivos, que é promover o desenvolvimento integral da criança.

Neste período, a análise da educação deve ser realizada considerando, mais do que nunca, as crianças e os jovens como um todo bio-psico-sociologicamente indivisível, com uma personalidade em interação com o seu desenvolvimento. Num contexto educativo, contamos com vários intervenientes para além da familiar, relevando-se a comunidade e a escola. "A escola é considerada um contexto ideal para a implementação de programas de promoção da AF" (SEABRA, 2017, p. 15).

A prática física regular no 10 ciclo, ou ensino primário - proporcionada na educação física escolar ou nas atividades desportivas e de dança em contexto escolar -, tem uma relevante inter-relação com as capacidades físico-motoras e também com a saúde do indivíduo. Estas práticas revertem-se em programas que sofrem amplas e profundas alterações ao longo da infância, para, mais tarde, assumirem características mais relacionadas com a procura do "bem estar" global do indivíduo nas dimensões física e psicológica. Rossetti-Ferreira et al. (2008) destacam que esta interação entre a pessoa e o meio ambiente contribui para que cada criança/jovem circunscreva os caminhos possíveis do seu desenvolvimento e aprendizagem individuais ou coletivos. Nestas ações as crianças adaptam-se e desenvolvem comportamentos que se pretende sejam positivos para uma adesão plena à atividade física, lúdica e expressiva, uma vez que com o tempo “... decrescem os níveis de atividade física em ambos os sexos, sendo que as meninas apresentam menores níveis de atividade física que os meninos em todas as faixas etárias mesmo entre em crianças em idade pré-escolar e escolar (...)" (SBP, 2008, p. 5).

Ao longo deste documento procuraremos realçar o papel da prática física na escola da Educação Básica - 1ำ Ciclo -, destacando o modelo de práticas sustentáveis. Cremos que a escola, enquanto espaço privilegiado de ação na educação da criança e do jovem, deve propor um conjunto de práticas físicas e motoras relevantes para as suas necessidades atuais, e pretendemos aqui ressaltar a prioridade de prepara para uma "educação ativa ao longo da vida", posto que o sedentarismo traz muitas consequências negativas para a saúde. Para Seabra (2017, p. 9), o sedentarismo é responsável pelo aumento das morbilidades e da mortalidade resultante de doenças crónicas degenerativas, relacionadas a um estilo de vida pouco ativo das populações (doenças cardiovasculares, cancro, diabetes e obesidade). 
A Região Autónoma dos Açores (RAA) que, pelas características da instrução da EF ou pelo desporto escolar infanto-juvenil, traz-nos algumas evidências sobre estratégias de melhoria dessas práticas na última década, em contraste com outras regiões do país, onde a prática física e motora, em algumas escolas do 10 ciclo, nem sempre é possível por meio de uma educação/formação desenvolvida na prática física curricular ou extracurricular. Primeiro, porque a educação física, em geral, não é lecionada em horário curricular, contrariando a legislação em vigor. Segundo, porque as atividades de recreio ao ar livre muitas vezes são reduzidas no tempo e no espaço. Por fim, porque a proposta é mais tardia (a partir do 2 ㅇ ciclo) nos programas de Desporto Escolar, com atividades que deveriam propor uma oferta em animação e iniciação à prática física e desportiva em várias modalidades significantes para a criança e a cultura da região em que vive, $\mathrm{e}$ não em substituição das práticas letivas.

Assim, sugerimos que se "espreite" a realidade delineada nas escolas do 1 으- ciclo da RAA, como um modelo de práticas que consideramos suportáveis porque tem permanecido mesmo após as mudanças operadas na educação na última década. Esta é uma oportunidade de se refletir os modelos de prática de atividade física e desportiva que, de uma forma estruturada, se propõem a criar melhores condições de vida às crianças, assegurando-Ihes uma equidade de oportunidades - criação de hábitos mais saudáveis e comportamentos mais ativos no âmbito da prática física, cultural e desportiva.

O nosso objetivo, com este trabalho, é realçar e refletir sobre os contextos de dois modelos complementares com importância na educação/formação da criança em desenvolvimento: a) o de uma Educação Física lecionada em horário curricular pelo professor especialista de Educação Física (EF) e, algumas vezes, pelo professor titular de turma; b) um Programa de Desporto Escolar em práticas que decorrem em atividades extracurriculares, propondo uma oferta em animação e iniciação à prática física e desportiva (AFD) em várias modalidades significantes para a criança, a sua saúde e a cultura da sua região.

\section{A ATIVIDADE FÍSICA NA ESCOLA Um Primeiro Passo de Educação e Saúde}

O início da educação básica escolar é um momento fulcral na educação para a atividade física (AF). A oferta na escola de um conjunto de práticas físicas, lúdicas e desportivas relevantes para as necessidades das crianças e jovens, está prevista no sistema educativo português.

As inúmeras vertentes de atividade física na escola - lúdica, artística, expressiva, desportiva e na saúde - são presumivelmente oferecidas por contextos variados: educação física, atividades de complemento curricular e no recreio. Nem sempre, porém, ocorrem estas várias janelas de oferta de oportunidade para a criança.

É uma realidade vivida no território insular, pois a Prática Física e Desportiva nas Escolas da Região Autónoma dos Açores (RAA) vivencia, segundo nosso conhecimento, "Um Modelo Sustentável para a Educação e Saúde", pois as Boas Práticas: Atividade Física e Desportiva nessas escolas açorianas advêm de um modelo de educação que 
se suporta em várias instituições (família, escola, sociedade) e que persegue um princípio: criação de bons hábitos de vida por meio de prática física diária mais saudável (Figura 1).

Figura 1 - Educação em contexto na RAA para bons hábitos de vida saudável

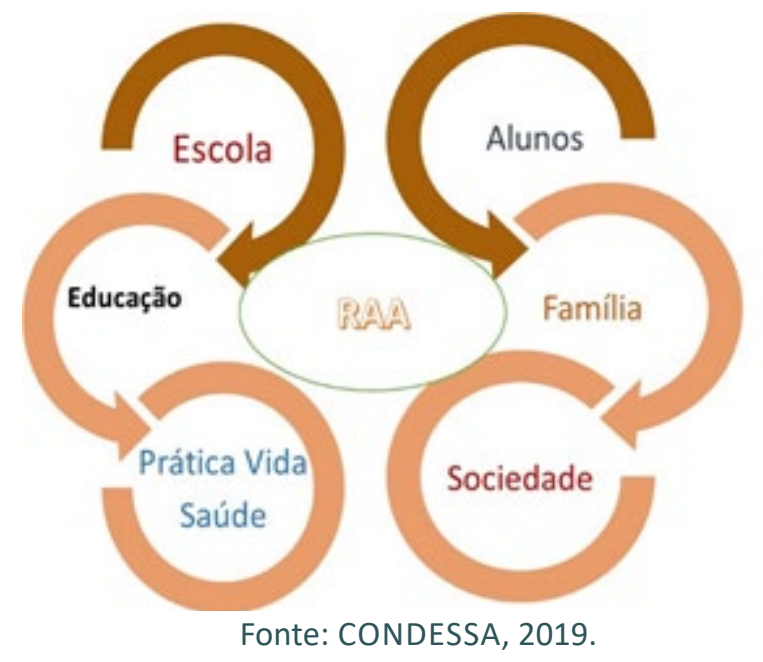

\section{O ENSINO DA EDUCAÇÃO FÍSICA NO 10 CICLO A Realidades das Escolas Açorianas}

Neste arquipélago de nove ilhas, as escolas das primeiras idades, ao contrário do resto do país, oferecem, em geral, uma Educação Física escolar na infância reforçada e que tem sido um modelo de boas práticas, pois não somente assume totalmente a existência da componente curricular da prática física e desportiva leccionada por professores especialistas, mas fortalece essa atividade com práticas extracurriculares de animação e iniciação desportiva de bom nível educacional, garantindo a crescente existência de um parque escolar desportivo cada vez mais condigno para a infância.

Para a Unesco, deve-se promover a Educação física para uma vida mais saudável, mais feliz, mais longa e mais produtiva. "As apostas são altas" - diz a diretora-geral da Unesco Irina Bokova -, “...o investimento público em educação física é muito compensado por altos dividendos em economia de saúde e objetivos educacionais", completa.

Neste sentido, Irina Bokova tem mostrado que a participação das crianças e jovens numa educação física de qualidade orienta-os para "... uma atitude positiva em relação à atividade física, diminuindo as chances de jovens se envolverem em comportamentos de risco e ter um impacto positivo no desempenho acadêmico, ao mesmo tempo em que fornece uma plataforma para inclusão social mais ampla.

A World Healthy Organization (WHO) apresenta este slogan num cartaz: "incresing physical ativity can prevent our children becoming obese. Less screen time, more play and recreation time is key", preocupando-se com o impacto do sedentarismo para as novas gerações.

Condessa (2015, p. 282) salienta que a escola pode ajudar as famílias a criar rotinas e hábitos às crianças e jovens que os ajudem a adotar um estilo de vida mais saudável, pois "a educação aí delineada irá ajudar o seu futuro...". 
Como ressaltado anteriormente, as áreas de preocupação particular identificadas pela Unesco sobre o estado da educação física foram muitas, e, conjuntamente com outras entidades (The European Commission, the International Council of Sport Science and Physical Education (ICSSPE), The International Olympic Committee (IOC), UNDP, Unicef, UNOSDP and WHO), apresenta sete pontos para refletir e melhorar:

1. Lacunas persistentes entre a política de EF e a sua implementação.

2. Deficiências contínuas na alocação de tempo do currículo.

3. Relevância e qualidade do currículo de EF.

4. Qualidade dos programas de formação inicial de professores.

5. Inadequações na qualidade e manutenção das instalações.

6. Barreiras contínuas à igualdade de provisão e acesso para todos.

7. Inadequada coordenação escola-comunidade.

A Educação Física no 10 ciclo na RAA tem lugar no horário estipulado para cada turma, estando alocado à EF "dois tempos" para o professor especialista e "um tempo" para o professor titular. $O$ professor de EF do $2^{\circ}$ ciclo concorre em concurso regional para professores: 1ำciclo - grupo № 110 - ou 2 Ciclo - grupo no 260 -, e não trabalha em atividades de complemento curricular, como ocorre no continente português, quando persistem lacunas de efetivação e barreiras para todos.

Reforçamos que na EF no 10 ciclo existem três pontos de grande realce na RAA:

1) os professores e o seu desempenho profissional;

2) os contextos (Espaços, Equipamentos, Materiais);

3) o reforço do programa com o Currículo Regional de Educação Básica.

A carga semanal da EF ainda é muito diminuta (três horas) quando comparada com o que seria desejável para trazer benefícios à saúde (todos os dias, pelo menos uma hora).

Quanto aos contextos de trabalho dos professores especialistas de EF, encontramos situações em que são verdadeiros "errantes" que andam de escola em escola; têm mais dez turmas sob sua responsabilidade, e um lugar de professor na zona ou escola integrada.

Os contextos de trabalho, relacionados quer com a adequação e a qualidade das instalações para a prática da EF, quer com a variedade e a qualidade do equipamento e dos materiais existentes, ainda deixam muito a desejar.

Matias e Condessa (2011), num estudo realizado no contexto escolar de 1 o ciclo na RAA, apresentam um relato de professor de EF no 10 Ciclo que se refere negativamente as suas condições de trabalho para lecionar:

"Não tem condições. Por exemplo, em situação de chuva ou mau tempo o espaço para a EF é um espaço exíguo muito pequeno, que onde uma turma de 20 alunos mal se mexe (...)" (Professor Celso).

Atualmente a situação persiste em muitas escolas. 
Em estudo na mesma comunidade, Andrade (2017) menciona: "A nível das escolas do 1을 Ciclo a realidade não é tão 'cor de rosa' como se pensa, principalmente nas escolas que não são alvo de intervenções de fundo há largos períodos de tempo. São as contempladas no Creb - relacionadas com as necessidades e cultura local".

Os espaços devem ser polivalentes, e, sempre que possível, cobertos e ao ar livre, em razão das características meteorológicas da região; os equipamentos e materiais devem ser escolhidos pela variedade de estimulação, tendo atenção à segurança da sua aplicação pensando na autonomia da criança.

No programa de EF (ME_DEB, 2004) com oito blocos de áreas de atividade, muitas ainda pouco trabalhadas (natação, percursos da natureza), deparamo-nos com uma extensão de propostas do Currículo Regional de Educação Básica (Creb) que trata a cultura regional como área a reforçar (danças regionais, jogos tradicionais e caminhadas em percursos pedestres).

Cremos que há um desafio que se coloca ao ensino da EF no 1ำ ciclo e esse passa pelo reforço de formação do professor - o generalista para a interdisciplinaridade -, quando a EF deve ser mais recorrente e o professor especialista para aprofundar mais áreas de atividade, como as que são contempladas no Creb - relacionadas com as necessidades do indivíduo perante a sua comunidade envolvente -, por exemplo, vastos campos verdes e tribos bem-delineados, piscinas naturais e lagos, variados grupos folclóricos e inúmeros jogos de infância adaptados às zonas e a sua população.

Conforme destaca Gonçalves (2014, p. 211) a "AF para todos só faz sentido quando todos têm as mesmas condições (infraestruturas, disponibilidades, transportes e acessibilidades) para a realizar." Por isso, consideramos relevante aproveitar os recursos naturais de cada região e o tempo de escola, quando todas as crianças devem ter as mesmas oportunidades.

\section{OUTRO TIPO DE PRÁTICA DE ATIVIDADE FÍSICA NO 10 CICLO Desafios nas Escolas Açorianas}

Os Açores foram pioneiros na promoção do desporto escolar em idades mais baixas, com o Programas de Animação e de Desporto Escolar: Projeto Escolinhas do Desporto, nas vertentes de animação e de iniciação desportiva, criado desde 2003. Este programa visa a contribuir para a criação de oportunidades de prática desportiva para as crianças com idades correspondentes ao 10 ciclo ou ensino primário, permitindo-lhes um primeiro contato com uma prática organizada e regular e os seus objetivos, que se encontram definidos no artigo 70 do Decreto Legislativo Regional no 21/2009/A, alterado em 2012 pelo DLR no 2, que são: (in)formar na cultura desportiva; incentivar à prática do desporto desde cedo; reforçar a importância do desporto - duplo sentido: desenvolvimento global e ativo e harmonioso das crianças e, por fim, ser um fator potenciador de um estilo de vida saudável. Aqui o "bem-estar", o divertimento e a iniciação na modalidade desportiva possibilitam também a integração em grupos e o iniciar da competição desportiva. 
Estes pequenos clubes de desporto escolar são geridos por professores ou técnicos com formação qualificada e, muitas vezes, em parceria com a comunidade local (clubes e associações desportivas). As competências desta orientação, à semelhança do que ocorre nos clubes de Desporto Escolar em âmbito Nacional, são inúmeras e em prol das boas práticas para as crianças e os jovens.

As escolinhas de desporto, projeto que iniciou há cerca de 15 anos, têm tido uma adesão elevada de crianças com idades entre 6 e 10 anos, integradas em núcleos de, pelo menos, 10 crianças; elas funcionam na escola, em horário extracurricular, com sessões de 1 hora e ocorrem duas vezes por semana, durante um período de 8 meses.

Atualmente, com tendência a crescer, o empenho neste projeto é grande. Em 2013/2014 havia cerca de 6.391 crianças inscritas, e em 2016/2017 o número subiu para 6.831, divididas em várias áreas de atividade: modalidades individuais e coletivas, atividades de ar livre, danças e atividades rítmicas expressivas e outras tipologias de atividades. Em 2014, a adesão às modalidades pelas crianças, segundo o Serviço de Desporto de uma ilha (da Direção Regional de Desporto) elevava para primeiro lugar as modalidades coletivas (45\%), para segundo as individuais $(19.1 \%$,$) , para terceiro as$ danças e atividades rítmicas expressivas (10.9\%) e, por fim, as modalidades de ar livre (5.4\%). Este projeto educativo, que contribui para o ProSucesso na região, contempla cinco acontecimentos anuais organizados pelo grupo escolar desportivo, pela associação desportiva e pelo serviço de coordenação de ilha, eventos coordenados pelas duas direções regionais: educação e desporto.

Segundo o responsável pelas escolinhas de desporto de uma ilha, "Esse é um projeto com um verdadeiro impacto na nossa região. É um projeto que não existe fora da região, é pioneiro, portanto. Mesmo a nível Europeu não tenho conhecimento que haja, apesar de poder até existir algo diferente. (...) Projeto esse que engloba a grande maioria dos nossos alunos (75 a 80\%) (...)" (ANDRADE, 2017).

\section{CONCLUSÃO}

Na escola, o envolvimento das crianças e jovens em práticas físicas e desportivas torna-se gratificante, sobretudo em momentos em que eles tendem a ter uma vida mais passiva e, por isso, a prática desta atividade é um elemento essencial ao desenvolvimento sustentado. Para Seabra (2017, p. 17), "a inatividade física em crianças é um grave problema de saúde pública".

Assim, consideramos que nos Açores:

- a "escola do 10 ciclo", numa perspetiva presente e futura, continua a ter um papel determinante na orientação e intervenção na atividade física e educação desportiva;

- a educação física na "escola do 10 ciclo", assegurada há mais de uma década pelos professores titulares e especialistas, cria equidade de oportunidades às crianças e jovens na "prática física", mas deve-se investir mais nas condições de trabalho;

- o projeto escolinhas de desporto continua a ser uma estratégia de promoção do sucesso educativo e de estilos de vida saudáveis. 
Com esta comunicação tivemos a oportunidade de refletir sobre estes dois modelos de prática de EF e AFD que, de uma forma sustentada, se propõem a conceber meIhores condições de vida às crianças, assegurando-lhes uma equidade de oportunidades - criação de hábitos mais saudáveis e comportamentos mais ativos.

\section{REFERÊNCIAS}

ANDRADE, J. V. "Construindo uma escola promotora de atividade física: um estudo em contexto de estágio. Relatório de Estágio em Educação Pré-Escolar e Ensino do 1ำ Ciclo. Ponta Delgada: Universidade dos Açores, 2017.

CONDESSA, M. I. C. A problemática da obesidade e da atividade física no desenvolvimento infantojuvenil: professores (in)capazes? In: SOUZA, E.; NASCIMENTO, J.; AZEVEDO, E.; PEREIRA, B. (org.). Educação Física, lazer e saúde: interfaces ao desenvolvimento humano. Florianópolis: Editora da Udesc, 2015. p. 277-298. V. 6. ()

GONÇALVES, E. A prática de atividade física de crianças/jovens e de seus familiares adultos na promoção da saúde: um estudo em três comunidades locais. 2014. Tese (Doutorado em Estudos da Criança) - Universidade do Minho, Braga, 2014.

MATIAS, H.; CONDESSA, I. The Curricular Physical Education in the Primary School. Analyze a context of teaching. In: CONGRESO DE LA ASOCIÁCION INTERNACIONAL DE ESCUELAS SUPERIORES DE EDUCACIÓN FíSICA (A CORUÑA 2010), COLECCIÓN CONGRESOS, CD 16., 543. Libro de Actas [...]. España: Editorial y Centro de Formación de Alto Rendimiento, 2011.

ME-DEB. Organização Curricular e Programas do Ensino Básico - 1o ciclo. 4. ed. Lisboa: Editorial do Ministério de Educação, 2004.

MOTA, J.; SALLIS, J. F. Actividade física e saúde. Factores de Influência da Actividade Física nas Crianças e Adolescentes. Porto: Campo das Letras, 2002.

ROSSETTI-FERREIRA, M. C. et al. Rede de significações e o estudo do desenvolvimento humano. Porto Alegre: Artmed, 2008.

SEABRA, A. A atividade física em crianças e adolescentes. Um comportamento decisivo para um estilo de vida saudável. Revista Factores de Risco, Lisboa, 12, n. 44, p. 9-20, abr./jun. 2017.

SBP. Sociedade Brasileira de Pediatria. Atividade física na infância e na adolescência: guia prático para o pediatra. Departamento Científico de Nefrologia da Sociedade Brasileira de Pediatria. 2008. Disponível em: http://www.sbp.com.br/src/uploads/2015/02/9667d-DOC-CIENT-AtivFisica.pdf. Acesso em: 2017.

THOMAS, J.; GALLAGHER, J.; THOMAS, K. Motor development and skill acquisition during childhood and adolescence. In: SINGER, R.; HAUSENBLAS, H.; JANELLE, M. Handbook of Sport Psychology. 2nd ed. New York: John Wiley \& Sons, Inc. 2001.

\section{Legislação Consultada}

Decreto-lei no 95/91, de 26 de fevereiro.

Lei de Bases da Atividade Física e Desporto - Lei no 5/ 2007 de 16 de janeiro.

Decreto Legislativo Regional no 21/2009/A. D.R. no 9, Série I de 2009-12-02.

Decreto Legislativo Regional no 2/2012/A. D.R. no 9, Série I de 2012-01-12.

Lei no 74/2013, de 6 de setembro - Diário da República no 172, Série I, de 06.09.2013.

Despacho no 9302/2014, de 17 de julho.

Sites consultados

CARTA Internacional da Educação Física e do Desporto da Unesco (1978). Disponível em: www.idesporto. pt/DATA/DOCS/LEGISLACAO/doc119.pdf. Acesso em: mar. 2008.

CONVENÇÃO dos Direitos da Criança. Disponível em: https://www.unicef.pt/docs/pdf_publicacoes/convencao_direitos_crianca2004.pdf. Acesso em: jul. 2014.

INCHEON Declaration for Education 2030. Disponível em: http://unesdoc.unesco.org/images/0024/002456/245656e.pdf. Acesso em: jun. 2018 